\title{
Preparing Catalogers for RDA Training
}

Alison Hitchens and Ellen Symons ${ }^{1}$

\section{Abstract}

This article prepares catalogers for the new cataloging standard Resource Description and Access (RDA) by giving trainers and Library and Information Science (LIS) educators the information they need to plan training for themselves and their staff or students. The theoretical principles of RDA are introduced as well as the corresponding vocabulary that trainers will need to use. This is followed by an overview of the structure of RDA as compared to the Anglo-American Cataloguing Rules (AACR2). Examples of rule changes and options are highlighted for trainers along with a reminder to review existing cheat-sheets and manuals that are based on AACR2. Finally, types of training formats are suggested.

Keywords: RDA, training, cataloging, FRBR, education

\section{Introduction}

Resource Description and Access (RDA) is the successor to the Anglo-American Cataloguing Rules (AACR), Revised 2nd ed. (AACR2R) and is due for publication in 2009. ${ }^{1}$ It is not the purpose of this article to critique RDA but rather to comment on how trainers, including Library and Information Science (LIS) educators, will need to prepare catalogers for

${ }^{1}$ Alison Hitchens is Cataloguing \& Metadata Librarian at University of Waterloo Library, Waterloo, Ontario N2L 3G1, email ahitchen@ library.uwaterloo.ca. Ellen Symons is Cataloguing/Training Librarian at Queen's University Library, Kingston, Ontario K7L 5C4, email symonse@queensu.ca. 
implementation. The descriptions and suggestions in this article are based on the November 2008 full draft of RDA, and contents may change before final publication of RDA. However, we hope that it will prompt catalogers, cataloging trainers and LIS faculty to think about training needs in advance of publication and implementation. After a brief background on changes in descriptive cataloging from AACR to AACR2R to RDA, we discuss the need for catalogers to know the theory underpinning RDA; we highlight changes to vocabulary, structure, and individual rules; and we comment on options and cataloger judgment in RDA. Finally, we touch on updates to inhouse training materials and give some suggestions about the format of RDA training.

\section{Background: From AACR to AACR2 to RDA}

A new edition of AACR has been in the works since the International Conference on the Principles and Future Development of AACR, held in Toronto, Ontario, in 1997. Work on RDA by the Joint Steering Committee for Revision of AACR (JSC) began in 2004 as AACR3 but quickly changed to its new title in 2005. Draft sections were released for comment between 2005 and 2008 with the full draft released in November 2008 for a final constituency review. JSC is striving to keep RDA in line with the Statement of International Cataloguing Principles ${ }^{2}$ and to ground the rules in the conceptual models Functional Requirements for Bibliographic Records $(\text { FRBR })^{3}$ and Functional Requirements for Authority Data (FRAD). ${ }^{4}$ According to the frequently asked questions (FAQs) on the JSC site, "RDA will provide:

-A flexible framework for describing all resources - analog and digital

-Data that is readily adaptable to new and emerging database structures

- Data that is compatible with existing records in online library catalogues." 
In other words, the new rules aim to allow catalogers to create metadata records for a variety of existing and emerging resources using principle-based rules without the need to re-catalog existing records.

In preparation for this article we conducted a literature search on publications that discussed the change from AACR to AACR2 and its impact on cataloging. The readings were a good review of the issues that arise when rules change and of the challenges pertaining to implementation and training. It was interesting to discover that many of the issues that drive the development of RDA today are the same issues that led to the publication of AACR2 back in 1978. Michael Gorman summarized the need for AACR3 (now RDA) in his 1997 article on the future developments of AACR. ${ }^{6}$ These include technological innovations, proliferation of nonbook materials, standardization, internationalization, and clarity. Similarly, Peter R. Lewis noted that AACR2 was brought on by concerns of non-book materials and internationalization, although he thought it stopped short of looking at the potential of new technology. ${ }^{7}$ We found that catalogers of that time prepared for AACR2 in the same way that we envision preparation for RDA; that is, by comparing structure and sequence of operations, ${ }^{8}$ highlighting departures from the previous set of rules, ${ }^{9}$ and commenting on the use of more cataloger judgment. ${ }^{10}$ Some articles consisted of overviews of principles, structural changes, and philosophical changes, ${ }^{11}$ while others described planning and implementation at individual libraries. ${ }^{12}$

At the time of writing this article, there were few publications available on RDA itself. Ann Chapman, ${ }^{13}$ Chris Oliver, ${ }^{14}$ and Lynne Howarth and Jean Weihs ${ }^{15}$ provide overviews of RDA, while Karen Coyle and Diane Hillman, ${ }^{16}$ and Michael Gorman ${ }^{17}$ offer critiques. Other articles address specific cataloging details, for example Laurence S. Creider discusses the inclusion of family names as access points in $\mathrm{RDA}^{18}$ In addition there are numerous news items 
in journals, magazines, newsletters, and blogs. ${ }^{19}$ Most information can be found on the JSC website, the body responsible for RDA. ${ }^{20}$ Much of the information on RDA consists of drafts, ${ }^{21}$ the FAQs from the JSC website, and presentations given at conferences. ${ }^{22}$ Trainers may also wish to join the RDA-L e-mail list ${ }^{23}$ for discussion of the rules.

\section{RDA theory}

In April 2005 the JSC decided to abandon the idea of AACR3 and replace AACR2 with a new cataloging standard (RDA) using FRBR as its foundation. FRBR came about as a result of the need to return to principle-based cataloguing that emphasizes essential user needs, as well as the need for a core level standard that would meet these needs and support national and international shared cataloguing programs. AACR was published in 1967 and was based on the Statement of Principles adopted at the International Conference on Cataloguing Principles, Paris, October 1961, commonly known as the Paris Principles. Part II of AACR2, published in 1978, was also based on the Paris Principles. In the four decades since AACR was first published, cataloging has changed a great deal. It has become automated, which has led to an increase in shared cataloging. One of the advantages of shared cataloging is to help reduce the cost of cataloging, but at the same time libraries are contributing more minimal level bibliographic records to national and international databases as another cost reduction. ${ }^{24}$ Along with these operational changes, cataloging now involves a much wider range of material types and information carriers, as well as the availability of new metadata standards. Cataloging rules now need to be independent of specific classes of materials, formats, and carriers and focus on putting content into data elements. In March 2009, the IFLA Meeting of Experts on an International Cataloguing Code (IME ICC) Planning Committee issued the final version of its Statement of 
International Cataloguing Principles, which updates the Paris Principles "from just textual works to all types of materials and from just the choice and form of entry to all aspects of bibliographic and authority data used in library catalogues." 25 It also states that these new principles build "on the great cataloguing traditions of the world, and also on the conceptual model in the IFLA Functional Requirements for Bibliographic Records (FRBR)."26

Before introducing RDA, trainers should take the time to familiarize catalogers with FRBR, because its terminology is used throughout RDA. FRBR is "an entity-relationship (ER) model ... three kinds of things are allowed in it: entities, attributes, and relationships. Entities are things, either physical or abstract. Thus, an entity can be virtually anything: relationships are interactions among entities; and attributes are properties or characteristics of entities or relationships." ${ }^{27}$ There are three groups of entities in the FRBR model. Group 1 entities are the products of intellectual or artistic endeavor (work, expression, manifestation, item - sometimes referred to as WEMI), while Group 2 entities are person and corporate body, or those who are responsible for content, production, or custodianship of Group 1 entities. Group 3 comprises all Groups 1 and 2 entities plus the entities concept, object, event, and place. All of these serve as subjects of intellectual or artistic endeavors, and form the basis for the Functional Requirements for Subject Authority Data (FRSAD). ${ }^{28}$

Although the FRBR model was first published in 1998, trainers should bear in mind that not all catalogers have had the opportunity to attend conference sessions on FRBR and/or RDA, nor have they all had time to follow the myriad of documentation published by IFLA and JSC and the ensuing discussion on cataloging lists and blogs. In addition, trainers must be aware of the differing levels of cataloger experience in their departments. For LIS students, the classroom 
may be the first place that they encounter FRBR. As a background to learning RDA, catalogers must understand that:

- RDA will include FRBR terminology for the Group 1 entities as well as terminology for Groups 2 and $3 ;^{29}$

- RDA will address FRBR relationships; and

- RDA will use FRBR user tasks (find, identify, select, obtain) as the basis for defining a core set of data elements.

Two of the primary objectives and principles related to the functionality of records intended by the use of RDA are responsiveness to user needs and relationships. "Responsiveness to user needs" relates to the four user tasks, defined in the FRBR model, that bibliographic records are intended to fulfill: find, identify, select, obtain. ${ }^{30}$ Thus, for example, Chapter 2 of Section 1 will help the user identify a manifestation or item, while Chapter 19 of section 6 will cover elements used to find a work. $^{31}$

Because FRBR is a conceptual model and can be difficult to grasp, trainers should use a concrete example to illustrate the model. A work of fiction that has several expressions and manifestations would be a good way to illustrate the user tasks and to use the new terminology. One example could be Pride and Prejudice, which has different editions, various film productions, translations, and audio recordings (see Figure 1). Trainers can use a FRBR implementation such as OCLC's FictionFinder prototype $\mathrm{e}^{32}$ to illustrate the relationships. FictionFinder allows the user to find what she is looking for, select the most appropriate manifestation, identify it as such by the description, and then obtain it through ILL. 


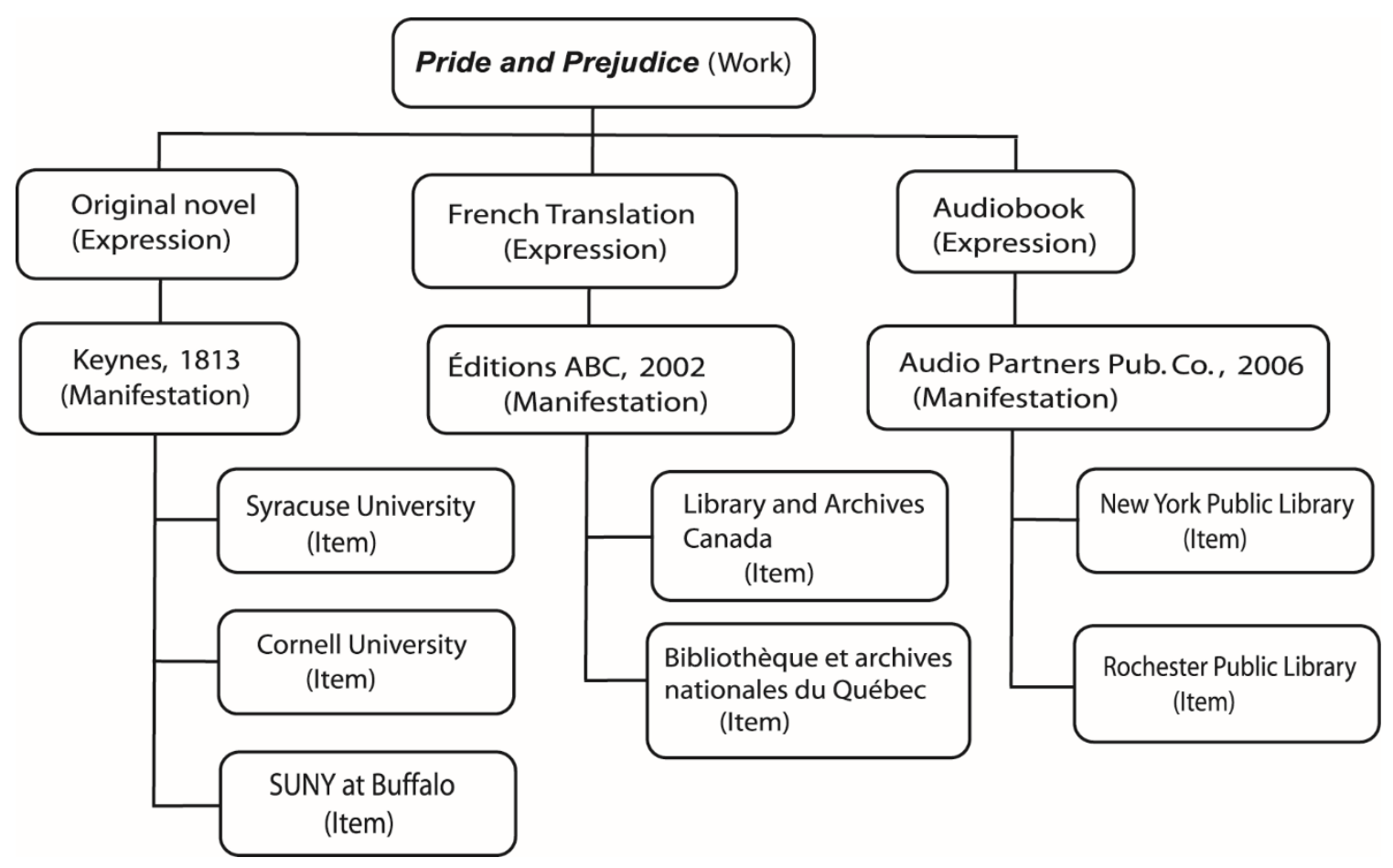

Figure 1: Illustration of FRBR using Pride and Prejudice

\section{Vocabulary}

The vocabulary found in RDA has changed to such an extent from that of AACR2 that catalogers might need some time to get used to it. The reorganization of RDA that took place in October 2007 aligned data elements more closely with the FRBR entities and user tasks, resulting in 10 sections divided into two groups. ${ }^{33}$ The section and chapter titles illustrate the use of FRBR terminology; for example:

Section 1: Recording Attributes of Manifestation and Item

Section 2: Recording Attributes of Work and Expression

Section 5: Recording Primary Relationships between a Work, Expression, Manifestation and Item

Chapter 1: General Guidelines on Recording Attributes of Manifestations and Items ${ }^{34}$ 
Trainers will have to ensure that catalogers are clear about the meaning of each FRBR term. As a result, catalogers will understand that the chapters in section 1 contain rules for recording such things as type of carrier (manifestation, chapter 3), and that chapters in section 2 instruct them on recording titles and access points in bibliographic and authority records. Trainers should also point out that terms are defined at the beginning of each chapter; for example, the definitions of work and expression are found at the start of chapter 5:

\section{“5.1.2 Work and Expression}

The terms work and expression are used as follows:

- The term work refers to a distinct intellectual or artistic creation

- The term expression refers to the intellectual or artistic realization of a work in the form of alpha-numeric, musical or choreographic notation, sound, image, object movement, etc., or any combination of such forms." 35

The online product demonstrated at the IFLA satellite meeting "RDA: Resource Description and Access: Foundations, Changes and Implementation" shows that catalogers will be able to click on new vocabulary words and go to the glossary to see their definitions. ${ }^{36}$

The new vocabulary in RDA is not limited to FRBR-related terms. For example, AACR2 refers to library materials, ${ }^{37}$ whereas RDA refers to these materials as resources ${ }^{38}$ For experienced cataloguers, trainers can show that although terminology has changed, the same information is being brought out in the description of the resource. 


\section{AACR2 vs. RDA terminology}

\section{AACR2 Terms}

area

element

heading

main entry

added entry

author/director/producer

/writer/compiler

uniform title

standard number

controlled heading

see/see from reference

\section{RDA Terms}

element

element sub-type

access point

access point for creator or title of a work

access point

creator

preferred title for a work

identifier

preferred access point

variant access point

Trainers should highlight the first use of a new term that differs from AACR2 and make sure that catalogers understand this term within the context of RDA. It would also be advantageous to start using the terminology in daily activities as soon as it has been introduced to staff or students; one has to use a new language on a regular basis in order to learn it! Catalogers can also use the features in the online environment of RDA to reinforce learning. These include functions that allow users to make notes and annotations, bookmark pages and create preferences, all of which will aid catalogers in learning new vocabulary and new rules. ${ }^{39}$

\section{RDA vs. AACR2: Changes in Structure}

Whether a cataloger is familiar with AACR2 or is new to cataloging, it is useful to give them an orientation to how RDA is structured. This will save time when trying to find specific 
rules and will highlight the cataloging process. For those familiar with AACR2, it will be useful if trainers give a comparison with RDA and show how the structure has drastically changed.

Trainers should start with the overall structure, which differs significantly from AACR2 (see table 1). Chapters are no longer based on format but on the elements of description for each FRBR entity. That is, rather than having a chapter for books and another for sound recordings and another for electronic resources, chapters cover identifying a work, expression, manifestation or item, the carrier of the resource, the content of the resource, and so on. This means that a cataloger will follow the same process no matter what material lands on his or her desk. It will be necessary to ignore rules that do not apply (e.g., ignore serials-related rules when cataloging monographs) or mask out irrelevant rules when using the online RDA tool. ${ }^{40}$ The selection and recording of access points is spread out over sections for work and expression, person, family, and corporate body.

Table 1: Comparison of Part I of AACR2 with Sections 1 and 2 of RDA

\begin{tabular}{||ll|}
\hline AACR2 & RDA \\
Part I: Description & Section 1: Recording attributes of manifestation and item \\
Chapter 1: General rules for description & $\begin{array}{l}\text { 1: General guidelines on recording attributes of } \\
\text { manifestations and items }\end{array}$ \\
Chapter 2: Books, pamphlets and printed sheets & 2: Identifying manifestations and items \\
Chapter 3: Cartographic materials & 3: Describing carriers \\
Chapter 4: Manuscripts & 4: Providing acquisition and access information \\
Chapter 5: Music & Section 2: Recording attributes of work and expression \\
Chapter 6: Sound recordings & 5: General guidelines on recording attributes of works and \\
expressions
\end{tabular}


In addition, the chapters are no longer based on the International Standard for Bibliographic Description (ISBD) ${ }^{41}$ areas of description (title and statement of responsibility area, edition area, physical description area, etc.). This means that catalogers who are following ISBD display will find rules related to their area of description scattered throughout RDA. For example, within the rules for the title element in RDA are rules on creating notes based on the titles. This combines information from the title and statement of responsibility area and the note area of the ISBD. Although it may be disorienting at first, this organization echoes the cataloging process in which catalogers are likely to make a note on the source of their title at the time of recording the title. Catalogers also need to be aware that examples are not generally given using ISBD punctuation. Examples demonstrate the content of the elements that are prescribed by RDA and it is up to the cataloger to put that content in whatever format has been chosen by the institution.

The sections on entities are followed by six sections for recording relationships; for example, the relationship between a work and the person who created the work. These chapters contain a mixture of instructions that in the MARC environment would populate both bibliographic and authority records. Trainers should also point out that chapters for the FRBR subject entities concept, object, and event have been left as placeholders; these entities are not generally part of descriptive cataloging. Only the chapter for the place entity, which is used in access points for government bodies and other names needing qualification, has been developed for the first edition of RDA. ${ }^{42}$ 
In addition to overall structure, trainers should highlight the internal organization of each chapter. Each section includes a general overview of the element, an overview of each subelement, and then specific details (see tables 2 and 3). For example, there are general rules for recording titles and then specific rules for recording the title proper. Catalogers need to make sure they are in the correct sub-section of the rules. Moreover, trainers should point out the inclusion of elements from other formats or modes of issuance that may not apply to the item in hand. For example, the title element includes a section on title changes that will not be relevant to most monograph catalogers (see title changes in table 3).

Table 2: Table of contents for section 2.3: Title

\begin{tabular}{||ll||}
\hline Rule \# & Contents \\
\hline 2.3 & Title \\
2.3 .1 & Basic Instructions on Recording Titles \\
2.3 .2 & Title Proper \\
2.3 .3 & Parallel Title \\
2.3 .5 & Other Title Information \\
2.3 .6 & Parallel Other Title Information \\
2.3 .7 & Earliant Title Variant Title \\
2.3 .8 & Later Variant Title \\
2.3 .9 & Key Title \\
2.3 .10 & Abbreviated Title \\
2.3 .11 & Devised Title \\
\hline \hline
\end{tabular}


Preparing Catalogers for RDA Training

Table 3: Table of contents for section 2.3.2: Title proper

\begin{tabular}{||ll||}
\hline \hline Rule \# & Contents \\
\hline \hline 2.3 .2 .1 & Scope \\
2.3.2.2 & Sources of Information \\
2.3.2.4 & Facsimiles and Reproductions \\
2.3.2.5 & Title in More Than One Language or Script \\
2.3.2.6 & Collective Title and Titles of Individual Contents \\
2.3.2.7 & Recording the Title Proper \\
2.3 .2 .8 & Other Elements Recorded as Part of the Title Proper \\
2.3 .2 .9 & Resource Lacking a Collective Title \\
2.3 .2 .10 & Resource With No Title \\
2.3 .2 .11 & Recording Changes in the Title Proper \\
2.3 .2 .12 & Major and Minor Changes in the Title Proper of Serials \\
\hline
\end{tabular}

It is common throughout RDA to include introductory guidelines and then specific instructions. Sometimes this takes the form of general rules followed by specific ones within a chapter, and other times an entire chapter introduces the chapters that follow, for example, chapter 8 introduces chapters 9 through 11. The linked online environment should aid in the navigation of these rules.

Catalogers may want to map commonly used rules from AACR2 to rules in RDA. Trainers could include an exercise such as "where did that rule go?" and highlight popular rules such as $21.1 \mathrm{~B} 2$ for corporate body main entry. Catalogers using the online version of RDA will be able to access a mapping table matching AACR2 and RDA rule numbers. ${ }^{43}$ When AACR1 
changed to AACR2 a rule mapping guide was written by Ronald Hagler, ${ }^{44}$ but catalogers may not need that level of detail in a searchable, hyper-linked online environment.

\section{Rule Changes}

As we have discussed, RDA represents a large change from AACR2 due to its alignment with FRBR and its goal of increased efficiencies in cataloging. As a result, experienced catalogers will need to consult RDA frequently and get back into the habit of looking up the rules for things that they know by rote. To emphasize this need, trainers should highlight the rule changes that affect everyday cataloging. For example, RDA takes a different approach to correcting inaccuracies. In AACR2 catalogers may correct errors in a title by using square brackets for a missing letter, by supplying the correction prefaced with “[i.e.]," or by

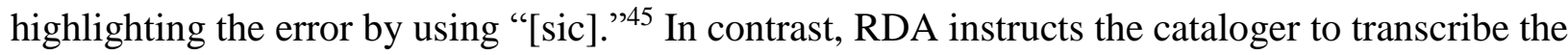
error as it appears and make a note to show the correction, as shown in the example below. ${ }^{46}$

$\begin{array}{ll}\text { AACR2: } & \text { The w[o]rld of pop } \\ \text { RDA: } & \text { The wrld of pop }\end{array}$

Note: Title should read The world of pop

One can still provide acces to the corrected title if considered important for access by using the rule for recording variant titles. ${ }^{47}$ Other examples of rule changes include:

- the elimination of the rule of three for author transcription and tracing, ${ }^{48}$

- the lack of allowable abbreviations throughout RDA (e.g., 8 bibliographic volumes in 5 physical volumes instead of $8 \mathrm{v}$. in 5), ${ }^{49}$

- significantly increased detail for describing the carrier, ${ }^{50}$

- a significant change in access points for parts of the Bible ${ }^{51}$ and 
- the rules for choosing access points of treaties. ${ }^{52}$

Trainers should choose rules that are relevant to their own institutions or curriculum with the most important message being, "Look it up!"

Changes in RDA will also affect MAchine Readable Cataloging (MARC) coding. There are several MARC discussion papers that deal with the effect of RDA on MARC bibliographic and MARC authority records. For example, the general material designation in AACR2, MARC 245 \$h, has been replaced by three new elements in RDA: media type, carrier type, and content type. ${ }^{53}$ Changes in the granularity ${ }^{54}$ of the data elements may lead to changes in MARC granularity; for example, a separate element for copyright dates and for dates associated with author names. ${ }^{55}$ Trainers will need to familiarize themselves with changes to MARC coding and pass these new tags and subfields onto cataloguers.

\section{Options}

In addition to understanding the theory and organization of RDA and having some knowledge of rule changes and new vocabulary, catalogers must know what to do when they encounter options in RDA. Options include three things: rules that are officially labeled “alternative," optional elements (vs. core elements), and phrases such as "if considered to be important for..." Examples in RDA include:

- the optional addition of secondary access points, ${ }^{56}$

- the optional use of ISBD and MARC,

- the option to leave out all but the first statement of responsibility relating to the title, ${ }^{57}$

- the option of accepting the capitalization from digital data sources, ${ }^{58}$ and

- the option to create author-title access points that incorporate all authors. ${ }^{59}$ 
North American catalogers are used to consulting Library of Congress Rule Interpretations ${ }^{60}$ (LCRIs) for guidance on options and for examples and detail when AACR2 is lacking. However, because the LCRIs are tied to specific AACR2 rules, presumably they will cease to exist with the implementation of RDA. It is not clear yet whether the majority of these options will be dealt with by standard practices at the national or international level (e.g., Program for Cooperative Cataloguing, practices of bodies such as the Library of Congress and Library and Archives Canada) or whether individual libraries will need to make significant policy decisions. Regardless of the source, catalogers need to be aware of options and what practice they should be following. LIS students can discuss options in class and consider the benefits of choosing one option over another.

For options that will be defined locally, cataloging departments need to meet with other library staff in order to determine the impact on Online Public Access Catalogs (OPAC) and discovery layers and the needs of their library users. For example, do reference staff want catalogers to provide access points for all authors associated with a resource, even if there are as many as 20 of them? Will this decision depend on the type of material or the type of content? Do cataloging departments have the time to deal with the authority work arising out of these decisions? Within the cataloging department it must be decided whether to accept derived copy that does not follow local decisions or edit all incoming records to meet those policies. For example, if someone downloads a record without a complete statement of responsibility, should the cataloger take the time to edit it? These are all things that need to be discussed in advance of cataloger training.

For options that take the form of "if considered important for...," catalogers are expected to rely on their own judgment. Depending on the culture of the cataloging department, this may 
or may not be something that catalogers are used to doing. RDA has been described as rules to aid cataloger judgment. ${ }^{61}$ Trainers should review the introduction to RDA, which lays out the functional objectives and principles of resource description that should aid catalogers in making these decisions. These include the ability of users to identify and find materials based on the records that have been created using the principles of sufficiency, differentiation, significant relationships, and accuracy. That is, has the cataloger provided sufficient information for the user to identify and obtain material?

\section{Editing Cheat Sheets and Manuals}

Deciding on and recording local policies is not new to cataloging, nor is providing catalogers with helpful guides to the rules. If you do a survey of technical services departments on the Internet, you will find many manuals, policies, and cheat sheets that have been created for catalogers, ${ }^{62}$ and as members of the AUTOCAT ${ }^{63}$ e-mail list we have noticed exchanges of cheat sheets among catalogers. This brings us to another task that must be done before training catalogers on RDA: trainers should either delete old manuals or bring them up to date with the current rules. Even for practices that have not changed, references to rule numbers must be updated. For example, at the University of Waterloo Library there is a guide to cataloging CDROMs, and simple statements such as "CD-ROMs are cataloged according to instructions in AACR 2 chapters 1 and 9"64 will need to be changed. The introduction of new rules provides a good opportunity to review training materials that have been accumulating over the years and assess which guidelines are adequately covered by RDA and which areas of cataloging warrant more guidance. Some cheat sheets may be replaced by RDA online's workflow ${ }^{65}$ features, which will guide the user through the cataloging process. 


\section{Training Formats}

To this point we have suggested the content of the training for RDA, but trainers also need to consider delivery of the content. Most of the literature on cataloging education discusses education at the library school level. However, Janet Swan Hill ${ }^{66}$ discusses different training formats that can be used for working catalogers. These include one-on-one training, group sessions when a new development comes along, or external sources such as vendor trainers and workshops. Another method of on-the-job training is to have the cataloger take a web-based course at her or his own desk. For example, Robert Ellett ${ }^{67}$ and Anna M. Ferris ${ }^{68}$ discuss separately the advantages of learning to catalog electronic resources through the OCLC Institute's online course Cataloging Internet Resources Using MARC21 and AACR2. RDA training can take place, to different extents, using all of the above formats.

In-house group sessions allow all catalogers within an institution or department to be trained at the same time and be at the same level of knowledge when RDA is introduced into their daily workflow. In order to implement this training, someone within the institution or department must be trained first so that they can provide the training to the rest of the staff. Organizations that are working on documentation and training issues include Library and Archives Canada, the Library of Congress, the British Library, the National Library of Australia, the JSC's Outreach Group, and the ALA Task Force on RDA Implementation. One goal of these groups is to produce "modules designed for distance education." ${ }^{69}$ The resulting documentation should allow designated catalogers to learn RDA well enough to train their staff.

RDA will be an online product, and it will have workflows to aid in training. The online product demonstrated at IFLA's RDA satellite meeting shows that there will be public workflows, such as Simple Books, which allow the cataloger to create a bibliographic record 
through step-by-step links to the appropriate instructions. ${ }^{\mathbf{7 0}}$ Experienced catalogers will be able to create their own workflows to use for self-training. Trainers can take advantage of this feature to design workflows suited to the needs of their department, which will be useful for training new catalogers and those learning to catalog new formats. As a follow-up, trainers might want to do some one-on-one training after catalogers have begun to use RDA. Similarly, LIS educators can create simple workflows to guide students through the cataloging process.

It is possible that workshops at the local or national level may take place around the time that RDA is implemented. Provincial or state library associations may organize training sessions, or opportunities may occur as pre-conference events at the national level. Heads of cataloging or technical services departments, or catalogers involved in technical services divisions of library associations, may want to take the initiative to organize these workshops at the local level because, as Rebecca L. Mugridge and Kevin A. Furniss said about authority work training, "[s]mall libraries often cannot afford to send employees to national conferences where they could take advantage of the many programs and workshops available ... therefore, regional workshops or conferences are the only recourse available to them."71

\section{Summary}

RDA constitutes a change to the rules that catalogers have been following for many years, and it embraces models that catalogers and cataloging faculty may not find as familiar as previous cataloging theories. Cataloging trainers in libraries and library schools can ease the transition to RDA by understanding the reasons the changes developed, the theories and principles underlying it, and by familiarizing themselves and their staff and/or cataloging students with the new structure, options, and rule changes. Trainers need to gather the relevant 
information and then present it to catalogers in a way that fits their workflow or instructional setting through workshops, discussions, and one-on-one training. The product itself will ease the transition with initial features such as RDA to AACR2 mapping, as well as mapping for RDA to MARC21. Trainers should also watch for guidance from their national cataloging bodies such as Library and Archives Canada or the Library of Congress. We hope that this article will encourage cataloging trainers and faculty to begin the process of preparing for RDA.

\section{Acknowledgments}

The authors would like to thank Zsuzsanna Lancsak, Matt Tales, Wayne Jones and the reviewers, for their valuable feed back. Thank you also to Clare Hitchens for her great copy-editing.

\section{Notes}

${ }^{1}$ Joint Steering Committee for Development of RDA (henceforth JSC), "RDA: Resource Description and Access: Background," http://www.rda-jsc.org/rda.html (accessed August 4, 2008).

${ }^{2}$ IFLA Meeting of Experts on an International Cataloguing Code, "Statement of International Cataloguing Principles,” 2009, http://www.ifla.org/files/cataloguing/icp/icp_2009-en.pdf (accessed August 4 , 2008).

${ }^{3}$ IFLA Study Group on the Functional Requirements for Bibliographic Records, Functional Requirements for Bibliographic Records: Final Report. UBCIM Publications, New series vol. 19, (Munchen: Saur, 1998), http://www.ifla.org/files/cataloguing/frbr/frbr.pdf (accessed August 4, 2008). 
${ }^{4}$ IFLA Working Group on Functional Requirements and Numbering of Authority Records, "Functional Requirements for Authority Data: a Conceptual Model: Draft 2007-04-01," http://www.ifla.org.sg/VII/d4/FRANAR-ConceptualModel-2ndReview.pdf (accessed March 23, 2009).

${ }^{5}$ JSC, "RDA: Resource Description and Access: Frequently Asked Questions: 1.3 Why did the name change to RDA-Resource Description and Access?" http://www.rdajsc.org/rdafaq.html\#1 (accessed August 4, 2008).

${ }^{6}$ Michael Gorman, "International Conference on the Principles and Future Development of AACR2," American Libraries 28 (December 1997): 24.

${ }^{7}$ Peter R. Lewis, “Introduction to AACR2: The Revision and Why It Is Needed" in Study School and National Conference Proceedings: Brighton 1978 (London: The Library Association), 40,44.

${ }^{8}$ Geoffrey Hamilton, "Structure of AACR2 and Changes from AACR1" in Study School and National Conference Proceedings: Brighton 1978 (London: The Library Association), 46-50;

Eric J. Hunter, AACR2: An Introduction to the Second Edition of the Anglo-American Cataloguing Rules (London: Clive Bingley, 1979).

${ }^{9}$ Hamilton, "Structure of AACR2," 48-49.

${ }^{10}$ Tina-Karen Alexia Weiner, "Introduction" in Anglo-American Cataloging Rules: One Year Later, ed. John T. Corrigan. Catholic Library Association Studies in Librarianship; no. 6 (Haverford, PA: CLA, 1982), 5.

${ }^{11}$ Patrice A. Stearley, “AACR 1 and 2” in Anglo-American Cataloging Rules, 11-20. 
${ }^{12}$ Georgina Brabec, "Coping with AACR 2" in Anglo-American Cataloging Rules, 21-30; Janet Swan Hill, "Northwestern University and Day One: A Catalog Maintenance Smorgasbord" in Anglo-American Cataloging Rules, 43-53.

${ }^{13}$ Ann Chapman, “RDA: A New International Standard," Ariadne 49 (Oct. 2006), http://www.ariadne.ac.uk/issue49/chapman (accessed August 6, 2008) and "RDA: A Cataloguing Code for the 21st Century," Library \& Information Update 7, no. 9 (Sept. 2008), http://www.cilip.org.uk/publications/updatemagazine/archive/archive2008/september/rdachapma $\underline{\text { n.htm }}$ (accessed December 28, 2008).

${ }^{14}$ Chris Oliver, “Changing to RDA,” Feliciter 53, no. 5 (2007): 250-53.

${ }^{15}$ Lynne C. Howarth and Jean Weihs, "Making the Link: AACR to RDA: Part 1: Setting the Stage," Cataloging \& Classification Quarterly 45, no. 2 (2007): 3-18, DOI:

10.1300/J104v45n02_02.

${ }^{16}$ Karen Coyle and Diane Hillman, "Resource Description and Access (RDA): Cataloging Rules for the 20th Century," D-Lib Magazine 13, no. 1/2 (2007), http://www.dlib.org/dlib/january07/coyle/01coyle.html (accessed August 6, 2008), DOI: 10.1045/january2007-coyle.

${ }^{17}$ Michael Gorman, “RDA: Imminent Debacle, ” American Libraries (Dec. 2007): 64-65.

${ }^{18}$ Laurence S. Creider, "Family Names and the Cataloger," Library Resources \& Technical Services, 51, no. 4 (Oct. 2007): 254-62.

${ }^{19}$ See for example Mark Needleman, "The Resource Description and Access Standard," Serials Review 34, no. 3 (Sept. 2008): 233-34.

${ }^{20}$ JSC, "RDA: Resource Description and Access," http://www.rda-jsc.org/rda.html (accessed August 6, 2008). 
${ }^{21}$ For a list of RDA drafts see http://www.rda-jsc.org/rda.html\#drafts (accessed August 6, 2008).

${ }^{22}$ A partial list of conferences can be found on the JSC website http://www.rdajsc.org/rdapresentations.html (accessed September 29, 2008).

${ }^{23}$ For information on the RDA-L discussion list see http://www.rda-jsc.org/rdadiscuss.html (accessed August 6, 2008).

${ }^{24}$ IFLA Study Group on the Functional Requirements for Bibliographic Records, Functional Requirements for Bibliographic Records: Final Report. UBCIM Publications, New series vol. 19, (Munchen : Saur, 1998), p. 1, http://www.ifla.org/files/cataloguing/frbr/frbr.pdf (accessed February 17, 2009).

${ }^{25}$ IFLA Meeting of Experts on an International Cataloguing Code, "Statement of International Cataloguing Principles," (2009), p. 1, http://www.ifla.org/files/cataloguing/icp/icp_2009-en.pdf (accessed March 14, 2009).

26 Ibid.

${ }^{27}$ Allyson Carlyle, "Understanding FRBR as a Conceptual Model: FRBR and the Bibliographic Universe,” Library Resources \& Technical Services 50, no. 4 (2006): 266.

${ }^{28}$ IFLA Working Group on Functional Requirements for Subject Authority Records (FRSAR), "Functional Requirements for Subject Authority Data (FRSAD): a Conceptual Model : 2nd Draft 2009-06-10,” http://nkos.slis.kent.edu/FRSAR/report090623.pdf (viewed July 7, 2009).

${ }^{29}$ RDA Section 4 (chapters 12-16), section 7 (chapter 23) and section 10 (chapters 33-37), as well as Appendix M, are placeholders for instructions on recording subject relationships. 
${ }^{30}$ JSC. "Purpose and Scope," RDA Constituency Review (Nov. 2008), rule 0.0, http://www.rdaonline.org/constituencyreview/Phase1Chp0_10_22_08.pdf (accessed February 17, 2009)

${ }^{31}$ JSC, "General Guidelines on RDA: Resource Description and Access," Home page, RDA Constituency Review (Nov. 2008), http://www.rdaonline.org/constituencyreview/ (accessed February 17, 2009).

${ }^{32}$ OCLC Online Computer Library Center Inc., FictionFinder, c2007 http://fictionfinder.oclc.org/ (accessed July 3, 2008).

33 JSC, "Historic Documents: A New Organization for RDA," http://www.rdajsc.org/docs.html (accessed October 5, 2008).

${ }^{34}$ JSC, "General Guidelines on RDA: Resource Description and Access Constituency Review" (Nov. 2008), Home page, http://www.rdaonline.org/constituencyreview (accessed January 27, 2009).

${ }^{35}$ JSC, “General Guidelines on Recording Attributes of Work and Expression,” RDA Constituency Review (Nov. 2008), rule 5.1.2, http://www.rdaonline.org/constituencyreview/Phase1Chp5_10_24_08.pdf (accessed January 27, 2009).

${ }^{36}$ Chris Oliver, "RDA: Resource Description and Access: Features \& Functionality" (presented at IFLA Satellite Meeting, Quebec City, QC, August 8, 2008), slides 27-28 of PowerPoint presentation, http://www.rda-jsc.org/docs/iflasatellite-20080808-demo.pdf (accessed October 12, 2008). 
${ }^{37}$ Anglo-American Cataloguing Rules. 2nd ed. (2002 revision with 2005 update). Prepared under the direction of the Joint Steering Committee for Revision of AACR. (Chicago: American Library Association, 2005), rule 0.21.

38 JSC, "General Guidelines on Recording Attributes of Manifestations and Items," RDA Constituency Review (Nov. 2008), rule 1.1.2, http://www.rdaonline.org/constituencyreview/Phase1Chp1_10_23_08.pdf (accessed January 27, 2009).

${ }^{39}$ Chris Oliver, “RDA: Resources Description and Access: Features \& Functionality”, slides 9-10 and 30-31; Patricia Longo, "Resource Description and Access: the Practical Impact of RDA”, (presented at Ontario Library Association Super Conference, Toronto, Ontario, February 2, 2008), slides 7-11 of PowerPoint presentation, http://www.accessola2.com/superconference2008/sat/1714/longo.ppt\#266,11,Online\%20Product \%20Functionalities (accessed March 14, 2009).

${ }^{40}$ Marjorie E. Bloss, "Resource Description and Access: RDA Activities since June 2007," RDA Forum, ALA Midwinter Conference, Philadelphia, PA, January 2008, slide 8 of PowerPoint presentation http://www.rda-jsc.org/docs/mb-philadelphia-20080113.pdf (accessed January 27, 2009).

${ }^{41}$ ISBD Review Group, International standard bibliographic description (ISBD). Preliminary consolidated ed. IFLA series on bibliographic control; vol. 31 (München: K.G. Saur, 2007), http://www.ifla.org/files/cataloguing/isbd/isbd-cons_2007-en.pdf (accessed September 29, 2008).

42 JSC, "General Guidelines on RDA: Resource Description and Access," Home page, http://www.rdaonline.org/constituencyreview/ (25 25 cessed February 17, 2009). 
${ }^{43}$ Nannette Naught, "RDA Product Development Snapshot: A Visual Tour of the Development Process" (paper presented at ALA Annual Conference, Anaheim, CA, June 28, 2008), slide 19 of PowerPoint presentation, http://presentations.ala.org/images/9/9a/RDAForumPresentation_Naught.ppt (accessed September 29, 2008).

${ }^{44}$ Ronald A. Hagler, Where's That Rule? A Cross Index of the Two Editions of the Anglo American Cataloguing Rules Incorporating a Commentary on the Second Edition and on Changes from Previous Cataloging Standards, (Ottawa, ON: CLA, 1979).

${ }^{45}$ Anglo-American Cataloguing Rules. 2nd ed. (2002 revision with 2005 update). Prepared under the direction of the Joint Steering Committee for Revision of AACR. (Chicago: American Library Association, 2005), rule 1.0F1.

${ }^{46}$ JSC, "General Guidelines on Recording Attributes of Manifestations and Items," RDA Constituency Review (Nov. 2008), rule 1.7.9, http://www.rdaonline.org/constituencyreview/Phase1Chp1_10_23_08.pdf (accessed December 28, 2008).

47 JSC, “Identifying Manifestations and Items," RDA Constituency Review (Nov. 2008), rule 2.3.6.1, http://www.rdaonline.org/constituencyreview/Phase1Chp2_11_6_08.pdf (accessed June 13, 2009)

48 JSC, “Identifying Manifestations and Items," RDA Constituency Review (Nov. 2008), rule 2.4.1.5, http://www.rdaonline.org/constituencyreview/Phase1Chp2_11_6_08.pdf (accessed December 28, 2008); and JSC, "Persons, Families and Corporate Bodies Associated with a Work," RDA Constituency Review (Nov. 2008), rule 19.2.1.3, 
http://www.rdaonline.org/constituencyreview/Phase1Chp19_11_10_08.pdf (accessed December 28, 2008).

${ }^{49}$ JSC, “Describing Carriers,” RDA Constituency Review (Nov. 2008), rule 3.22.2.8, http://www.rdaonline.org/constituencyreview/Phase1Chp3_11_2_08.pdf (accessed December 28, 2008).

50 Ibid.

${ }^{51}$ Anglo-American Cataloguing Rules. 2nd ed rule 25.18A; JSC, "Identifying Works and Expressions," RDA Constituency Review (Nov. 2008), rule 6.23.2.9, http://www.rdaonline.org/constituencyreview/Phase1Chp6_11_12_08.pdf (accessed December $28,2008)$.

52 Anglo-American Cataloguing Rules. 2nd ed., rule 21.35A; JSC, "Identifying Works and Expressions," RDA Constituency Review (Nov. 2008), rule 6.29.1.15, http://www.rdaonline.org/constituencyreview/Phase1Chp6_11_12_08.pdf (accessed December $28,2008)$.

${ }^{53}$ JSC, "Encoding RDA, Resource Description and Access Data in MARC 21, Marc discussion paper no. 2008-DP-04, Section 3.1 (2007), http://www.loc.gov/marc/marbi/2008/2008-dp04.html (accessed September 29, 2008). ${ }^{54}$ Granularity refers to how the data is subdivided when coded; finer granularity means providing specific subfields or codes for each piece of descriptive information rather than gathering several elements together within one subfield.

${ }^{55}$ Ibid., sections 3.4, 3.15.2. 
${ }^{56}$ JSC, “General Guidelines on Recording Relationships to Persons, Families, and Corporate Bodies Associated with a Resource,” RDA Constituency Review (Nov. 2008), rule 18.3, http://www.rdaonline.org/constituencyreview/Phase1Chp18_10_31_08.pdf (accessed December 28, 2008).

57 JSC, "Identifying Manifestations and Items," RDA Constituency Review (Nov. 2008), rule 2.4, http://www.rdaonline.org/constituencyreview/Phase1Chp2_11_6_08.pdf (accessed December 28, 2008); and JSC, “General Guidelines on Recording Attributes of Manifestations and Items," RDA Constituency Review (Nov. 2008), rule 1.3, http://www.rdaonline.org/constituencyreview/Phase1Chp1_10_23_08.pdf (accessed December $28,2008)$.

${ }^{58}$ Ibid., rule 1.7.1.

59 JSC, “Identifying Works and Expressions," RDA Constituency Review (Nov. 2008), rule 6.27.1.3, http://www.rdaonline.org/constituencyreview/Phase1Chp6_11_12_08.pdf (accessed December 28, 2008).

${ }^{60}$ Office for Descriptive Cataloging Policy. Library of Congress Rule Interpretations. 2nd ed. (Washington, DC: Cataloging Distribution Service, 1989).

${ }^{61}$ Chapman, "RDA: A New International Standard.”

${ }^{62}$ See for example the cataloging websites for York University www.library.yorku.ca/ccm/Biblio/catcom/index.htm and Yale University www.library.yale.edu/cataloging/ (accessed September 29, 2008)

${ }^{63}$ AUTOCAT. Subscribers send e-mail to autocat@listserv.syr.edu. See the list archives at http://listserv.syr.edu/archives/autocat.html. 
${ }^{64}$ University of Waterloo Library. Cataloguing Department. Cataloguing CD-ROMS, 2006. http://www.lib.uwaterloo.ca/staff/cat/electronic.html (accessed September 29, 2008).

${ }^{65}$ Nannette Naught, "RDA Product Development Snapshot,” slide 22.

${ }^{66}$ Janet Swan Hill, "Education and Training of Catalogers: Obsolete? Disappeared?

Transformed?" Published in two parts. Technicalities 24, nos. 1 and 2 (Jan./Feb. and March/April 2004): 10-15, 9-13.

${ }^{67}$ Robert Ellett, “An Evaluation of the Effectiveness of OCLC Online Computer Library Center's Web-Based Module on Cataloging Internet Resources Using the Anglo-American Cataloging Rules and MARC21," in Education for Cataloging and the Organization of Information: Pitfalls and the Pendulum, ed. Janet Swan Hill (Binghamton, NY: Haworth, 2002): $311-38$.

${ }^{68}$ Anna Ferris, "Cataloging Internet Resources Using MARC21 and AACR: Online Training for Working Catalogers," in Education for Cataloging and the Organization of Information: Pitfalls and the Pendulum, ed. Janet Swan Hill (Binghamton, NY: Haworth, 2002): 339-53.

${ }^{69}$ Marg Stewart, email to authors, November 20, 2007.

${ }^{67}$ Chris Oliver, "RDA: Resources Description and Access: Features \& Functionality," slide 23.

${ }^{68}$ Rebecca L. Mugridge and Kevin A. Furniss, "Education for Authority Control: Whose Responsibility Is It?," in Education for Cataloging and the Organization of Information: Pitfalls and the Pendulum, ed. Janet Swan Hill (Binghamton, NY: Haworth, 2002): 242. 